Rating Therapists Who Treat Substance Abusers

Pekka Saarnio, Ph.D., Senior Lecturer

Department of Social Policy and Social Work

University of Tampere

P.O. Box 607

FIN-33014 University of Tampere

Finland

Mikko Mäntysaari, Ph. D., Docent, Head of Research and Development

National Research and Development Centre for Welfare and Health (Stakes)

P.O. Box 220

FIN-00531 Helsinki

Finland

In press: International Social Work 


\begin{abstract}
Service users' views on service production are nowadays considered essential. However, not much is known about these evaluative processes in the treatment of substance abuse. This study includes two experiments and a qualitative analysis of therapists' $(\mathrm{N}=4)$ written responses which were used as basic material in the experiments. The first experiment focused on the therapists' ability to feel empathy, their genuineness, their respect for the client and their concreteness. In the second experiment, the raters put the therapists in order of preference. The qualitative analysis showed that the therapists' written responses differed from one another in length and style. However, they were thematically similar. To some extent the results of the experiments converged: The two most popular therapists were the same in both experiments. The therapist who got the highest scores wrote the longest responses and the one who got the lowest scores wrote the shortest responses. The length of the responses had a connection with the length of the therapist's work experience: The longer the experience, the shorter the responses, though the more concise. The age of the raters had no connection with the results. Gender had some impact in the first experiment. Combining these rating methods with an analysis of outcome and continuity of substance abuse treatment would be an interesting theme for a further study.
\end{abstract}




\section{Rating Therapists Who Treat Substance Abusers}

Research on the personal qualities of therapists who treat substance abusers has been scarce in social work literature. This is surprising considering that differences in efficiency due to the personal qualities of therapists have a major impact on the outcome of psychotherapy (Luborsky et al. 1986; Roth \& Fonagy 1996). And yet, even research on psychotherapy has to a much lesser extent focused on the examination of therapists' personal qualities than it has on the examination of clients' qualities (Garfield 1997).

Valle's (1981) study on the connection between the interpersonal skills of therapists treating substance abusers and clients' relapses after the treatment is a classic in the field. The therapists were first examined with regard to four qualities, utilizing the principles drawn up by Carkhuff and Berenson (1977): 1) empathy, 2) genuineness, 3) respect, and 4) concreteness. On the basis of the results, the therapists were divided into three groups, and the coping of their clients was monitored over a period of two years.

The share of relapses grew in each group in the course of the follow-up period, but the share had a consistent connection with the therapist's qualities: The better his or her interactional skills, the fewer relapses there were among the clients. The same tendency has been identified in later studies: Therapists' interactional skills and the quality of the client-therapist 
relationship are of great importance with regard to the outcome of therapy (Connors et al. 1997; Horvath 2000; Najavits \& Weiss 1994; Project ... 1998a, 1998b).

Against this background, it is not surprising that there is a connection between the therapist's style of acting and the continuity of treatment. Garfield et al. (1963) conducted a study with six subjects, who were all therapists, with four new clients. Three independent outside raters ranked the therapists with regard to how effective they were in creating an interactive relationship during the first therapy session. Only one quarter of the clients of the two most effective among the therapists interrupted the treatment, while as many as three quarters of the two least effective therapists interrupted their treatment. In the case of the therapists placed in the middle, half of the clients interrupted the treatment. Similar findings have been reported in research on substance abuse treatment: Nielsen et al. (2000) concluded that therapist's style with empathic and reflective listening is a good predictor of clients' compliance with treatment.

At least in the Finnish context, interruption of therapy also seems to have a connection with the therapist's gender (Saamio et al. 1998). This was detected in a study that was implemented in an institution for substance abusers. Clients were assigned to therapists in order of arrival without any bias. Interruption was significantly more common among the clients of male therapists than it was among clients of female therapists. It was not possible 
to conduct a more detailed investigation into the background of the phenomenon on the basis of the data. However, one possible explanation is that female therapists were more skilled in avoiding critical situations that lead to interruptions.

Clients are very interested in the way their therapists treat them. Saarnio et al. (1996) conducted an experiment simulating this in connection with a study on the impact of solution-oriented training. The members of the research team were requested to put the research subjects in order of preference with regard to whose clients they would have wanted to be. There were marked differences in the popularity of the subjects, even though the information the research team members received about them was very limited.

The aim of this study was to test and compare two methods for rating therapists' personal qualities. The study is methodologically important for further research on outcome and continuity of substance abuse treatment. The first author of this article, P. Saarnio, is doing research on the connection between therapists' personal qualities and the continuity of substance abuse treatment (Saarnio, forthcoming). The method used in experiment 1 is a part of ongoing study. In addition to two rating experiments, the study includes a qualitative part, in which therapists' written responses are analyzed. We will start by reporting the results of the 
qualitative analysis, and only after that, turn our attention to the results of the experiments.

\section{Therapists' written responses}

The data used in the rating experiments consisted of the written responses of four therapists who treat substance abusers. The therapists were selected randomly among the staff of a Finnish institution for substance abusers, but with the precondition that the same number of men and women were included in the study (Table 1). All participants had taken part in therapy training. With the exception of therapist number 3 , the distribution of length of work experience with substance abusers was fairly even among the therapists.

Insert Table 1 about here

The data were collected utilizing the method developed by Valle (1981); this method resembles the method of role-playing (Eskola 1997). The therapists were given five initial narrations, vignettes, told by substance abusers or their relatives. They were asked to complete these stories by writing how they would have acted in the situations in question. There was no limitation to how long they could take to provide their responses. The vignettes were direct translations of the stories used by Valle. 
1. "I wish everybody would stop talking to me about drinking. So I have a few too many drinks once in a while. If my wife would stop nagging me about the bills and the kids and everything else, I wouldn't have to drink. If she would just shut up."

2. "Please tell me what to do to get my sister to stop drinking. I have tried everything but nothing works. What am I going to do?”

3. "I know I love him, why, I remember when we would spend all weekend together fishing or building something in the backyard. But he's not like that anymore and when I see him on the streets, I try to avoid him. Even my friends are making jokes about him. Mom says he's sick, but if he's sick, why isn't he in the hospital? I just don't know what to say to him, or how I should feel. After all, he is my father."

4. 'Lately, it seems we're always leaving parties early and I find myself worrying about what my wife will do or say instead of enjoying my friends. Then we talk about it the next day and she always says she doesn't remember. She's really been acting strange lately... and I wonder, well, do you think she could have a drinking problem? I know she's not an alcoholic because she can go without a drink for weeks, but when she does drink, well..." 
5. “I can't do it, I can't stay sober. No matter how hard I try, I can only get a few weeks together. I might just as well admit I'm a no good bum.” Qualitative analysis of therapists's responses

$\underline{\text { Method }}$

After the therapists had written their responses to the above presented vignettes, the first author of this article, P. Saarnio, decided that this research project could gain benefits from a qualitative content analysis of therapists' responses. He suggested this task to M. Mäntysaari, who had had no prior contacts to the therapists and did not know anything about their past professional careers or personl qualitities. Mäntysaari implemented the qualitative analysis separately, so that the results of the quantitative analysis could not affect the results of the qualitative analysis. Only after the first qualitative analysis round, a meeting between the researchers was held in which the results of the qualitative coding of the data were compared with the results of the quantitative analysis.

An application of the Grounded Theory (Strauss \& Corbin 1997) was used in the analysis. The texts were screened for codes, which were then recoded and recombined with one another in an attempt to find axial codes. These were used to draw up an explanatory model, which explicates what the data reveals. In practice, the analysis was carried out so that the therapists' responses were written out and saved as separate files. The next step was to analyze the data by using repeated codings utilizing the indexing 
property of the LaTeX text processing program, as well as making free searches for word combinations by means of the grep text searching program.

$\underline{\text { Results }}$

The therapists who took part in the study produced differing written responses. Both the length and the style of the texts varied a great deal. The length varied from a quarter of a page to two pages. Although the therapists got the same instructions as guidance for their writing assignment, their reflections were stylistically different: Some wrote as if they were answering in a discussion-like manner to the person speaking in the vignette, others focused more on what a therapist could do in the situation described.

As Table 2 shows, the answers given by therapist 4 were longest, while those given by therapist 3 were shortest. The answers given by therapists 1 and 2 were in between these two in length.

Insert Table 2 about here

The number of codings for answers was largest in the case of therapist 2. The second largest number of codings was found in the answers of therapists 1 and 4 . The lowest number of codings was found to the answers of therapist 3. However, if we compare the number of codings with the length of the answers, the situation looks different. In comparison to the length of the text, the number of codings was the same in the case of 
therapists 1, 2 and 3, while the ratio was far smaller in the case of therapist 4. The answers of therapist 4 were to some extent more difficult to code than were the answers of the other therapists.

No social context was given when allocating the assignment, and this may have had an impact on how the therapists read the texts. It is difficult to say what kind of impact additional information about the clients' social circumstances would have had on the therapists' interpretations.

Although their responses varied in style and length, as described above, the therapists seem to have reacted to the vignettes according to a fairly uniform pattern. Their texts often start with an interpretation of the client's situation, followed by the possible explanations for the client's drinking. After this the therapist generally reflects upon how to help the client. Some of the writers also try to find alternative interpretations for the reasons for drinking as well as to the recommendable steps to be taken.

In the responses of therapists 1 and 2, the interpretation of the situation is presented in the form of a conversation with the client. An example of therapist 1's style follows; this is her answer to the fourth vignette:

It is natural that you should be concerned about what your wife does or says. But it is your wife who bears the primary responsibility for the things you mention. 
Therapist 3 uses a totally different approach when writing. He writes as if he were an outsider, observing what could happen in the situation described. An example of his writing follows:

We are probably dealing with some sort of substance abuse here. What shows this is the way she drinks. They should talk about the matter within the family. It may be difficult but not impossible; it takes guts to do it. An honest and open attitude and discussion seems to be called for. (Taken from the fourth response of therapist 3)

Therapist 4 also uses a similar way of making comments. However, the answers are stylistically quite different. While therapist 3 uses a brief and concise style, the answers of therapist 4 are long and meandering:

- What about if the situation continues like this, what would happen to this person, to this relationship, to the feelings; creation of conflict.

- Discussion on codependency, on a change process, on the nature of the substance abuse, on caring and on possibilities. 
- There should be no pointing at the guilty ones, but looking at things objectively, facing facts.

- Have they discussed the matter together? Has he expressed his concern? How? Has he helped her? (Taken from the fourth response of therapist 4)

After making interpretations of the situation and reflecting upon it, the therapists gave their recommendation or guidelines for steps to be taken. Irrespective of whether written in dialogue form (therapists 1 and 2) or as reflections of an outsider (therapists 3 and 4), these guidelines moved along very similar lines.

A common instruction for steps to be taken was to seek help at a Finnish outpatient treatment organization called the A-clinic or in an AA group. Therapists 1 and 4 particularly used this strategy, while therapists 2 and 3 mentioned a self-help group only once.

The close relatives in your situation have founded an Al-Anon group where they can unravel their feelings. You can also attend the meetings of this group and listen to other people's experiences of the same thing. (Taken from the second response of therapist 1) 
Therapist 4 also recommended self-help groups:

- Is it possible to attend Al-Anon meetings? And how about seeking help for yourself, would it help the sister? (Taken from the second response of therapist 4)

Therapists 1, 2 and 3 all recommended the use of the different services of an A-clinic, but therapist 4 made no reference to an A-clinic.

Moralizing won't help the sister; it generally only causes the defense mechanisms to start to function and there is a need to show that I don't have any problems. Objective information about intoxicants could make the sister find out about an A-clinic, and she could then little by little start working out her substance abuse problem. (Taken from the second response of therapist 3)

In their answers, therapists 2 and 3 made recurrent references to motivation and its importance, while therapists 1 and 4 never took up the matter of motivation.

$\underline{\text { Discussion }}$ 
There is a specific structure which is common to the texts of all four therapists; it is discernible irrespective of whether the therapist has written the text in the form of a dialogue or as an outside commentator.

First, comments were made on the situation of the imaginary client, and after that, possible solutions or action strategies were sought. Regarding action strategies, the focus was on recommending the client seek help at an A-clinic or in various self-help groups.

There were some differences in the breadth of the answers. Therapist 3 differed from the others because of the briefness of his answers and therapist 4 because of the length of her answers. There were also stylistic differences: The answers of therapist 3 were concise and full of information, while therapist 4 reflected upon things at great length in her answers. Therapist 2 emphasized the importance of creating motivation more than the others did.

\section{Experiment 1}

\section{$\underline{\text { Method }}$}

The aim of the experiment was to rate the therapists' responses using the method of Carkhuff \& Berenson (1977). The raters $(\underline{N}=15)$ were students of social work taking a course in social work skills in the University of Tampere, Finland. Their average age was 26 years $(\underline{\mathrm{SD}}=6, \min =21$, $\max =43$ ). The number of women was 11 and of men 4 . 
The raters were first asked to read the therapists' responses carefully through. After this they were to familiarize themselves with an excerpt from Carkhuff and Berenson's (1977) book in which the different rating dimensions are presented: 1) empathy, 2) genuineness, 3) respect, and 4) concreteness. Valle (1981) used these same rating dimensions in his study. There were twenty separate texts altogether, and four ratings were made of each of them. Each rater was thus to make eighty different ratings. A ninestep numerical scale was used in the rating. There were no limitations to the time for providing the answers.

\section{$\underline{\text { Results }}$}

If we look at the sum variable derived from the rating scores (Figure 1), we can conclude that the scores of therapist 1 and therapist 2 were at the same level, while the sum score of therapist 4 was significantly higher and that of therapist 3 lower. The vignette-based differences between the therapists were similar; except in the case of the fifth vignette, the results of therapist 1 and 2 were nearly identical, and those of therapists 3 and 4 were on both sides of them (Figure 2). The -reliabilities of the therapists' vignette-based overall scores varied between .90 (therapist 1) and .97 (therapist 4), which shows that the raters were very consistent.

Insert Figures 1 and 2 about here

The differences between the therapists were similar regarding the rating dimension-based sum variables (Figure 3). The -reliabilities between the 
different dimensions varied between .88 (therapist 1) and .96 (therapist 2). The order among the therapists was also discernible in the scores they received for each vignette of the rating dimensions.

Insert Figure 3 about here

The age of the raters had no connection with the scores given, but gender did have an impact on the ratings given to therapists 1, 3 and 4. According to $\underline{\mathrm{t}}$-tests, men gave more positive $(\underline{\mathrm{p}}=.05)$ ratings to therapists 1 and 3 than did women if we look at the sum scores. A more detailed examination showed that men rated both therapist 1 (vignettes $2,3,4)$ and therapist $3(1$, $2,3,4)$ to be more genuine. A similar difference was found in the case of therapist 1 regarding her ability to feel empathy (2) and respect for the client (3). In addition, men found therapist 3 more concrete $(1,2,3)$. According to t-tests, women's rating scores were significantly higher than those of men only on two points, which both concerned therapist 4: genuineness in vignette 3 and respect for the client in vignette 1 .

\section{$\underline{\text { Discussion }}$}

On the basis of this experiment, the order of the therapists was clear: Therapist 4 got consistently the highest scores and therapist 3 the lowest ones. Therapists 1 and 2 were on an equal level between these two. The same order can be seen in the sum, the vignette as well as rating dimension scores. Valle (1981) came to similar conclusions: There are marked differences between therapists. 
Reliability coefficients show that the ratings were very consistent. Gender had an impact on the ratings given to therapists 1, 3 and 4. Men gave more positive ratings to therapists 1 and 3, particularly regarding genuineness and concreteness. Women gave more positive ratings to therapist 4 for genuineness and respect. The gender of the raters and those to be rated had no consistent interaction.

When examining the results, we underline the fact that the raters were at the beginning of their careers in social work. However, this is not very important factor when these results are considered. The students are intended to represent service users views of therapists' style and skills, and we do not consider them as professional peer reviewers. However, it is obvious that the students' style of rating may have a connection with their development of skills of social work. In an earlier study, it was concluded that at least the style of responding is connected with the development of social work skills: Students and novices of social work produced much longer written answers than did experienced social workers when asked to analyze interaction in social work (Saarnio 1993). The answers were also stylistically different: The answers of students and novices resembled answers in examination papers, while the answers of experienced professionals were concise with a focus on essential matters.

The length of work experience and the length of the written responses were in inverse relation to one another even in the data of this study. 
Therapist 3 had long work experience and the shortest responses. Therapist 4, in turn, had short work experience and the longest responses. In addition, she was the youngest among the therapists.

The problem of raters' competence in social work cannot be resolved by using this design. However, a study in course of preparation indicated that there were no differences between students and experienced social workers in a similar rating task (Saarnio, forthcoming).

\section{Experiment 2}

$\underline{\text { Method }}$

The aim of the experiment was to assess the therapists' texts by using the method of Saarnio et al. (1996). The raters $(\underline{N}=12)$ were students of social work taking a course in social work skills in the University of Tampere, Finland. They were not the same persons as those in the first experiment. Their average age was 26 years $(\underline{\mathrm{SD}}=5, \min =21, \max =37)$. Except for one, the raters were women.

The raters were first asked to read through the therapists' texts carefully and after that to assess them individually with regard to whose clients they would want to be in their own affairs. In other words, they were to put the therapists in order of preference. There were no limitations as to how long they could take to answer.

\section{$\underline{\text { Results }}$}


Table 3 shows the results of the experiment. Therapist 4 was by far the most popular one, since as many as ten raters put her first. Therapist 2 was second most popular and therapist 3 third. Half of the raters ranked therapist 1 fourth, in other words, last.

Insert Table 3 about here

The age of the raters did not have a connection with the results, even though two of the raters who put therapist 4 last were older than the raters on average, in other words, 28 and 31, a man and a woman. They put therapist 2 first. The impact of gender could not be assessed, as there was only one man among the raters.

\section{$\underline{\text { Discussion }}$}

The experiment showed a clear order of preference. Saarnio et al. (1996) obtained similar results using the same method; in other words, there were marked differences between the therapists. Therapist 4 was most popular, therapist 2 second, and after them, therapists 3 and 1 . There were no changes in the positions of therapist 4 and 2 in comparison with the first experiment, but therapists 1 and 3 changed places. It may be that this was caused by the differences in the general test arrangements. The concise style of therapist 3 focusing on the essential probably inspired the raters with confidence in the second experiment.

Age did not have a systematic connection with the rating results. The two raters who put therapist 4 last were older than average, and this could be an 
indication of the fact that raters with wider experience of life do not favor novices. However, the problem cannot be resolved by using this kind of raters. It would require a greater and more even variation of age among them. The importance of gender could not be analyzed because of the small number of men among the raters.

\section{General discussion}

The study included two experiments which rated therapists who treat substance abusers and also a qualitative analysis of the material that was being rated. The qualitative analysis showed that the therapists' written responses differed from one another in length and style. However, they were thematically very similar. The first experiment rated the therapists' empathy, genuineness, respect and concreteness. In the second experiment, the raters put the therapists in order of preference. The results of the experiments showed some convergence: The two most popular therapists were the same in both experiments. The therapist who got the highest scores wrote the longest responses and the one who got the lowest scores wrote the shortest responses. The length of the responses had a connection with the length of the therapist's work experience: The longer the experience, the shorter the responses, though concise. The age of the raters had no connection with the results. Gender had some impact in the first experiment.

The results showed that there were significant differences between the therapists. Naturally, it is not possible to draw conclusions on what these 
differences between therapists mean with regard to outcome or continuity of therapy when treating substance abusers. This problem is addressed in another study currently under construction (Saarnio, forthcoming).

Project Match showed significant therapist effects in client outcomes (Project ... 1998a, 1998b). 'Outlier' therapists whose caseloads showed unusually poor outcomes accounted for most of the observed effects. The Project Match Research Group recommend that in future studies of therapist effects, analyses should specifically take into account the possible impact of 'outlier' therapists. This is also important from a practical viewpoint: Looking in the mirror is necessary. Once the staff of a treatment unit decide that outcomes and patient dropouts are also their problems, effective intervention can begin (Carroll 1997; Craig 1985).

The rating methods used in the experiments were well-functioning as such. However, one should be critical when using them. There is reason to suspect that raters' own competence in social work has an impact on the results. In other words, persons at different stages of competence in social work may have different kinds of preferences regarding therapists' differing responses. When considering this question, there are several issues to be taken into account: First, the social work students were not supposed to act as professional peer reviewers but as representants of service users in general. Second, the experimental design used in this study did not afford the opportunity to ascertain whether beginners favor novice therapists and 
experienced raters experienced therapists. This is an interesting problem from the viewpoint of practice as well as research. However, a study in course of preparation indicated that there were no differences between students and experienced social workers in a similar rating task used in experiment 1 (Saarnio, forthcoming). The importance of raters' gender and age is also worthy of closer examination.

A question of totally different dimensions is what sort of data should be used when ratings such as this are made. In this study the data consisted only of therapists' written responses. Nonverbal communication plays an essential role in human interaction, and this is also true of therapeutic interaction (Burgoon et al. 1996; De Roten et al. 1999; Lieberman 2000). Because of this, it can be claimed that written inputs to a fictional client situation cannot give enough data for the evaluators to rate the therapists. This problem can be considered by comparing possible research materials on therapeutic interaction (Saarnio 1997). At least five different versions can be carried out: 1) transcribed text 2) audiotape, 3) videotape, 4) observation through a screen, 5) observation in the interaction situation. The fifth version is, of course, the most authentic, including everything from smell to temperature. It is also likely to be the one to cause the strongest emotional reactions, but at the same time, it is possible that these reactions impair observation of interaction. This might be the added value of the fourth version. The third version, the viewing of the videotape, gives 
even more perceptual and emotional distance for the evaluators. It can be said offhand that the two first versions are more scarce than the others, and the first one producing least material for the evaluators.

However, Valle's (1981) study showed the validity of a rating based on written material. Both of the rating methods used in this study proved wellfunctioning, internally coherent, and they also yielded largely similar results, thus providing a good point from which to go on. 


\section{References}

Burgoon, J., Buller, D., \& Woodall, W. (1996). Nonverbal communication. The unspoken dialogue. New York: McGraw-Hill.

Carkhuff, R., \& Berenson, B. (1977). Beyond counseling and therapy. New York: Holt, Rinehart and Winston.

Carroll, K. (1997). Improving compliance with alcoholism treatment. NIAAA. Project Match Monograph Series Vol. 6. Rockville, Maryland: NIAAA.

Connors, G., Carroll, K., DiClemente, C., Longabaugh, R., \& Donovan, D. (1997). The therapeutic alliance and its relationship to alcoholism treatment participation and outcome. Journal of Consulting and Clinical Psychology, $\underline{65}, 588-598$.

Craig, R. (1985). Reducing the treatment drop out rate in drug abuse programs. Journal of Substance Abuse Treatment, 2, 209-219.

De Roten, Y., Darwish, J., Stern, D., Fivaz-Depeursinge, E., \& CorbozWarnery, A. (1999). Nonverbal communication and alliance in therapy: The body formation coding system. Journal of Clinical Psychology, 55, 425-438. 
Eskola, J. (1997). Eläytymismenetelmäopas [Guidebook on the method of role-playing]. Tampere: Tampereen yliopisto.

Garfield, S. (1997). The therapist as a neglected variable in psychotherapy research. Clinical Psychology: Science and Practice, $\underline{4}$, 40-43.

Garfield, S., Affleck, D., \& Muffly, R. (1963). A study of psychotherapy interaction and continuation in psychotherapy. Journal of Clinical Psychology, 19, 473-478.

Horvath, A. (2000). The therapeutic relationship: From transference to alliance. Journal of Clinical Psychology, 56, 163-173.

Lieberman, M. (2000). Intuition: A social cognitive neuroscience approach.

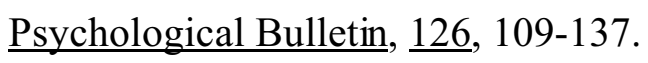

Luborsky, L., Crits-Christoph, P., McLellan, A., Woody, G., Piper, W., Liberman, B., Imber, S., \& Pilkonis, P. (1986). Do therapists vary much in their success? Findings from four outcome studies. American Journal of Orthopsychiatry, $\underline{56}, 501-512$. 
Najavits, L., \& Weiss, R. (1994). Variations in therapist effectiveness in the treatment of patients with substance use disorders: An empirical review. Addiction, $\underline{89}, 679-688$.

Nielsen, B., Søgaard Nielsen, A., \& Wraae, O. (2000). Factors associated with compliance of alcoholics in outpatient treatment. Journal of Nervous and Mental Disease, $188,101-107$.

Project Match Research Group (1998a). Therapist effects in three treatments for alcohol problems. Psychotherapy Research, $\underline{8}, 455-474$.

Project Match Research Group (1998b). Matching patients with alcohol disorders to treatments: Clinical implications from Project Match. $\underline{\text { Journal of }}$ Mental Health, 7, 589-603.

Roth, A., \& Fonagy, P. (1996). What works for whom? A critical review of psychotherapy research. New York: Guilford Press.

Saarnio, P. (1993). Kokeellinen tutkimus sosiaalityön taitojen kehittymisestä [An experimental study of the development of social work skills]. Janus, $\underline{1}, 49-60$. 
Saarnio, P. (1997). Sosiaalityön vuorovaikutuksen tutkimisesta [Measuring interaction in social work]. Perheterapia, $\underline{13}$, 34-39.

Saarnio, P. (forthcoming). The early therapeutic alliance and the continuation of substance abuse treatment.

Saarnio, P., Aareskoski, K., Kojo, S., Koskinen, H., Lehto, P., Tamminen, M., Tulensalo, H., \& Ylänen, T. (1996). Ratkaisukeskeisen koulutuksen vaikutuksia [Effects of brief therapy education]. Perheterapia, 12, 22-28.

Saarnio, P., Tolonen, M., Heikkilä, K., Kangassalo, S., Mäkeläinen, M.-L., Niitty-Uotila, P., Vilenius, L., \& Virtanen, K. (1998). Päihdeongelmaisten selviytyminen hoidon jälkeen [Coping after inpatient treatment of substance abuse]. Sosiaalilääketieteellinen Aikakauslehti, $\underline{35}$, 207-219.

Strauss, A., \& Corbin, J. (1997). Grounded theory in practice. Thousands Oaks: Sage.

Valle, S. (1981). Interpersonal functioning of alcoholism counselors and treatment outcome. Journal of Studies on Alcohol, $\underline{42}$, 783-790. 
Table 1.

Background information on therapists $(\mathrm{N}=4)$.

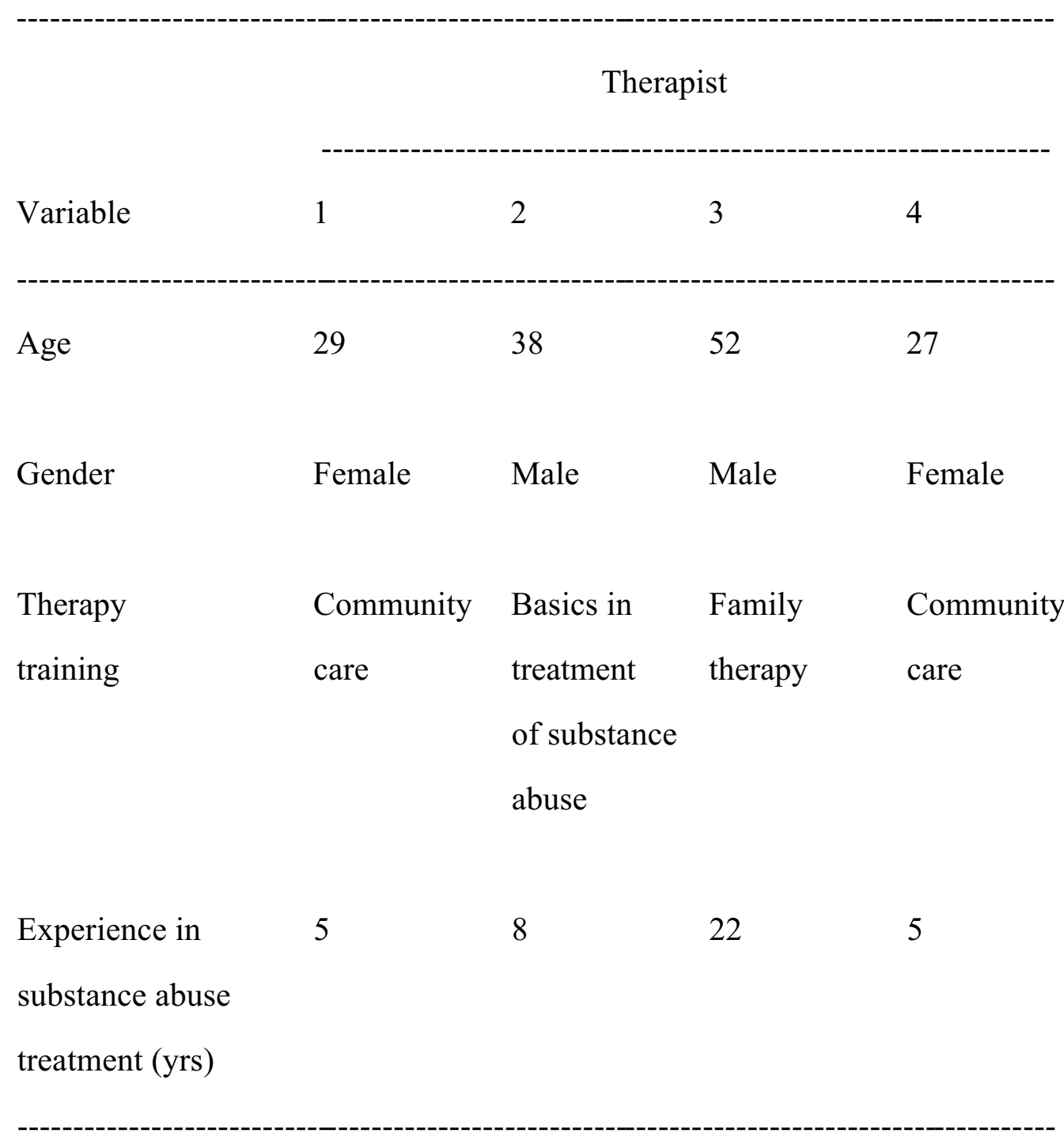


Table 2.

The overall number of words in the therapists'

$\underline{\mathrm{N}=4) \text { responses and the number of codes }}$

included in them.

\begin{tabular}{|c|c|c|c|c|}
\hline \multirow[b]{2}{*}{ Vignette } & \multicolumn{4}{|c|}{ Therapist } \\
\hline & 1 & 2 & 3 & 4 \\
\hline 1 & 66 & 198 & 57 & 260 \\
\hline 2 & 73 & 102 & 86 & 166 \\
\hline 3 & 86 & 153 & 90 & 203 \\
\hline 4 & 96 & 170 & 47 & 139 \\
\hline 5 & 103 & 96 & 81 & 155 \\
\hline Total & 424 & 719 & 361 & 923 \\
\hline Codes & 18 & 26 & 14 & 17 \\
\hline Codes / n & 0.04 & 0.04 & 0.04 & 0.02 \\
\hline
\end{tabular}


Table 3.

$\underline{\text { Raters' }(N=12) \text { individual ratings with regard to }}$ $\underline{\text { which therapist's }(\mathrm{N}=4) \text { clients they would want }}$ to be in their own affairs $(1=$ most desirable, $4=$ least desirable). The numbers indicate the sum of the preference categories for each therapist (e.g. $\underline{\text { ten raters put therapist } 4 \text { first and two put her }}$ fourth).

\begin{tabular}{|c|c|c|c|c|}
\hline \multirow[b]{2}{*}{ Therapist } & \multicolumn{4}{|c|}{ Order of preference } \\
\hline & 1 & 2 & 3 & 4 \\
\hline 1 & & 2 & 4 & 6 \\
\hline 2 & 2 & 8 & 1 & 1 \\
\hline 3 & & 2 & 7 & 3 \\
\hline 4 & 10 & & & 2 \\
\hline
\end{tabular}


Figure 1. The means of the sum variable derived from the rating scores given to the therapists $\underline{\mathrm{N}}=4)$. According to a repeated analysis of variance, there was a statistically significant $(\mathfrak{p}<.001)$ difference between the therapists. Analysis of contrasts indicated statistically significant $(\mathfrak{p}<.05)$ deviations from overall mean in therapists 3 and 4. 
Figure 2. The means of the vignette-based sum variables derived from the rating scores given to the therapists $(\underline{N}=4)$. According to repeated analyses of variance, there were statistically significant $(\underline{p}<.001)$ vignette-based differences between the therapists. 
Figure 3 . The means of the rating dimension-based sum variables derived from the rating scores given to the therapists $(\underline{N}=4)$. According to repeated analyses of variance, there were statistically significant $(\underline{p}<.001)$ rating dimension-based differences between the therapists. 